\title{
A RELAÇÃO DOS MUSEUS DE CIÊNCIAS COM ESCOLAS
}

\author{
CERQUEIRA, B.S'; BARZANO, M. A. L. ${ }^{2}$
}

\section{Bolsista PIBIC/FAPESB, Graduanda em Ciências Biológicas, Universidade Estadual de Feira de Santana, e-mail: bia02_biologia@yahoo.com}

\section{Orientador, Departamento de Educação, Universidade Estadual de Feira de Santana, e-mail: marco.barzano@gmail.com}

\section{PALAVRAS-CHAVE: Museu de Ciências; Escolas; Espaço não-formal}

\section{INDRODUÇÃO}

Por muito tempo atribuiu-se ao espaço escolar como o único lugar de aprendizagem, sendo a sala de aula o ambiente onde conhecimento do professor era transmitido ao aluno. Porém, há muito tempo que esta informação não é verdadeira.

Com as rápidas e constantes transformações sociais e tecnológicas em nossa sociedade, e no ambiente escolar, foi aos poucos agregando as novas formas de educação, sem deixar que interferisse diretamente em seu espaço de formação dos jovens. Dentro desse contexto, estão inseridos os museus, transmitindo conhecimento de forma descontraída, tornando esse espaço de aprendizagem mais lúdico para o aluno, deixando-o livre para suas próprias indagações acerca do que for visto e poder relacionar com o que foi aprendido em sala de aula.

Os museus, nas últimas décadas, tiveram interesse ampliado, não só em relação à órgãos educacionais, sejam governamentais ou privadas, como também por parte do público em geral (CHAGAS, 1993). O papel dos museus de ciência e tecnologia vem emergindo no movimento de alfabetização cientifica dos cidadãos e atualmente, tornou-se indispensável acrescentar a exploração educativa do seu conjunto material e simbólico (QUEIROZ et all 2003).

Com base nisso, este projeto teve a intenção de ampliar a investigação na pesquisa concluída que aborda a relação museu-escola. Apresenta como objetivo, compreender e analisar as exposições nos museu e escolas, suas impressões sobre o público visitante e a divulgação da ciência que estes espaços podem repercutir, nos mais variados âmbitos sociais, bem como sua contribuição para o currículo escolar

A pesquisa, de cunho qualitativo, foi desenvolvida a partir da realização de entrevistas com a intenção de coletar dados para a maior compreensão e análise das relações existentes entre Museus (espaços de educação não formal) com o ambiente escolar (educação formal).

O número reduzido de pesquisas nessa área torna este trabalho muito importante, onde muito se sabe sobre os trabalhos desenvolvidos nos espaços do museu, porém apresenta poucas publicações sobre a relação museu-escola.

\section{MATERIAL E METODOS}

O presente estudo foi realizado pelo período 1 (um) ano - Agosto de 2015 a Julho de 2016. Foram realizadas visitas ao museus: Museu Casa do Sertão e Observatório Astronômico Antares - localizados em Feira de Santana; e Jardim Zoobotânico - em Salvador.

Realizou-se visita guiada, afim de se conhecer a estrutura do local, seus materiais expostos e qual o foco que os monitores abordam ao público visitante. Os roteiros guiados eram agendados previamente pelo professor (ou responsável pela turma) por telefone e confirmadas 
por e-mail, confirmando dados do professor, perfil dos alunos que participarão da visita e qual objetivo da visita.

As visitas ocorreram durante o período letivo e em horário comercial (09-12h e 14-17h) e os grupos de alunos não ultrapassaram 30 alunos por monitor, por conta da logística da abordagem e apresentação do conteúdo. Para cada faixa etária, os monitores adequavam seu foco, roteiro e linguagem para transmissão do conteúdo aos alunos.

Os professores foram entrevistados em diferentes momentos, afim de se conhecer sobre o motivo da visita nos museus e suas expectativas sobre o aprendizado dos aluno. Algumas entrevistas ocorreram antes da visita ser realizada e em outras, ocorrerem na escola, após o grupo já ter visitado o espaço do museu.

Durante a realização das entrevistas foi informado aos entrevistados que estas seriam gravadas. Para a realização da entrevista foi utilizado os roteiros de perguntas por meio de um questionário semiestruturado, que tinha como interesse saber os dados do professor visitante, formação básica, tempo de atuação e interesse em levar o aluno para este espaço. Foram selecionados 5(cinco) escolas de cada museu, que havia realizado visitas recentemente e dentre estes, foram entrevistados um total de 15 professores.

Com o objetivo de analisar qual(is) interesse(es) que levam o docente a recorrer a uma visita ao museu, optamos por uma pesquisa de cunho qualitativo, pois, esta trabalha com o universo de significados, motivos, crenças, atitudes, e dos fenômenos que não podem ser reduzidos à operacionalização de variáveis (MINAYO, 1996). Neste tipo de pesquisa, o pesquisador anseia saber o porquê dos acontecimentos, sem levar em conta a quantidade de valores e suas trocas simbólicas ou possivelmente colocá-las à prova.

A pesquisa do tipo qualitativa, como relatado por pesquisadores como Godoy (1995) apresenta no mínimo, três possibilidades: pesquisa documental, estudo de caso e etnografia. Dentre estas, foi eleita para análise e posterior processamento dos dados o estudo de caso a qual segundo Lüdke e André (1986) o estudo de caso tem a possibilidade de perceber a situação social, representando os diferentes e, também, conflitantes pontos de vista e ações inerentes à situação estudada.

\section{RESULTADOS E DISCUSSÕES}

As entrevistas foram realizadas no final do segundo semestre de 2015 e no primeiro semestre de 2016. Constatou-se que os docentes pesquisados são professores licenciados nos cursos de: Ciências Biológicas, História, Geografia e Letras Vernáculas. Possuem entre 5 a 15 anos de formação e atuam na área que foram formados. Do total pesquisado, 10 (dez) destes lecionam em escola particular e 5 (cinco) pública.

A intenção na visita por parte dos professores foi variada. Mais da metade deles, levaram seus alunos por conta de algum projeto existente na escola e estes projetos em suma eram ligados à área de ciências, com alguns temas associados ao indivíduo e sociedade. Outra parcela dos docentes, estavam aproveitando a temática para abordar, algo que já foi visto em sala. Facilidade no acesso e proximidade com as escolas foram os principais fatores que contribuíam para a realização da visita e escolha do museu visitado, e também com a possibilidade de ver o animal de perto (zoológico).

Pelo posicionamento dos professores, verificou-se que as visitas apresentavam um motivo específico, como utilizar o espaço para a continuação de um projeto ou mesmo para a complementação dos estudos escolares. Os docentes apresentaram expectativas positivas, em relação aos recursos existentes (material exposto, animal para observação), que auxiliam as 
atividades realizadas na escola e tem o potencial de subsidiar o ensino formal, como enfatizado por Willison (2003).

Como Constantin (2000) afirma, a instituição escolar, por si só, não apresenta condições de proporcionar à sociedade a (in)formação técnico-científica e humanística necessária à leitura do mundo. Além disto, nenhuma instituição por si só consegue arcar com essa demanda, uma vez que as crianças, bem como os adultos, necessitam de motivação e estímulos permanentes.

Os alunos foram preparados antes de iniciar a visita ao museu, com instruções quanto a vestimenta, o comportamento e o objetivo da visita.

As visitas geralmente são frutos de algum projeto existente na escola. Por conta disso o estudante terá que apresentar algum devolutiva ao retornar a escola, seja em forma de relatório, relato ou seminário. Esta pratica ocorre para que o aluno não acredite que este momento é simplesmente uma 'fuga' da sala de aula.

Sobre o espaço ser adequado para o que se destina a exposição, alguns professores afirmaram sobre:

Museu Casa do Sertão - “(...) achei o ambiente pequeno e um pouco apertado e a entrada é um pouco escondida, mas consegue transmitir o que se propõe";

-“os materiais expostos trazem uma transposição de conhecimento, de identidade e de valores que existiam há algumas décadas atrás, que é muito válido apresenta-los aos alunos”

Observatório Astronômico Antares - "o espaço é fantástico e as réplicas (dos dinossauros) tornam tudo muito real e interessante de mostrar aos alunos";

-“o ambiente é amplo, arejado, bem sinalizado e cumpre bem o esperado.”

Jardim Zoológico - ambiente agradável, porém deveria apresentar uma quantidade maior de animais expostos e que este estejam disponíveis e bem visíveis para o público visitante".

$\mathrm{Na}$ fala destes docente é possível perceber a visão de finalidade antropocêntrica sobre o espaço ambiental e que a natureza é meramente um recurso econômico com finalidades recreativa. Segundo ALMEIDA (2008), a perspectiva antropocêntrica congrega a maior parte dos argumentos favoráveis a essas instituições e basta se pensar no modo como são definidas: jardins zoológicos e parques afins são locais públicos que exibem animais com as finalidades recreativa e educativa.

Dos 15 professores entrevistados, 12 deles estavam inseridos em algum projeto de ciências na escola e, a partir daí, resultou a visita ao museu. Para os professores que não participaram de algum projeto na escola, a visita ocorreu por motivação da disciplina e a estes, não havia apoio da escola quando a deslocamento. Para isso, era combinado com os alunos de estarem na hora marcada no museu. Esta pratica é comum em Feira de Santana, pois o museu Antares e a Casa do Sertão são de fácil acesso, contanto com ônibus urbano nas proximidades do museu. O mesmo não acontece com o Zoológico de Salvador que, por conta da distância, necessita de ônibus que realize esse translado.

Para 6 (seis) deles, acreditavam que levar os alunos em zoológicos e museus relacionados, incutem no aluno a sensação de preservação ambiental. Para 5 (cinco) professores, acreditam que o aluno não internaliza esse assunto por não ter sido devidamente trabalhado em sala e pela visita não apresentar esse foco. Para os demais, não se aplica, pois o foco da visita é apenas mostrar que os animais existem e que museu não está estruturado para causar este tipo de indagação pelos alunos. 
Esse posicionamento está em sintonia com o valor atribuído por Kellert (1997), no que se refere aos diferentes tipos de apropriação ligadas à natureza e como estas podem que ser avaliadas numa dimensão distinta do seu interesse para a aprendizagem científica. Entretanto, as experiências indireta e simbólica de contato com a natureza não constituem alternativa à experiência direta. Na experiência indireta, falta intimidade, desafio, criatividade e participação ativa dos encontros diretos com o ambiente.

Para os jovens em idade escolar, a ida ao museu de ciências atrai a curiosidade sobre temas vistos em sala de aula, ou oriundo de algum projeto escolar, onde o que é aprendido na escola consegue adquirir uma dimensão mais próxima e mais agradável. Apropriando-se desse ambiente não-formal de educação, os professores realizam seus projetos, afim de não só facilitar a difusão do conhecimento para os alunos mais jovens, abordando temas, visto no ambiente escolar com uma cara menos séria que o ambiente exige

\section{CONSIDERAÇÕES FINAIS}

Nesta pesquisa analisamos por meio das entrevistas como se estabelece a relação museuescola buscando compreender como se origina a construção significativa do ensino aprendizagem por meio das interações colaborativas para a aprendizagem entre os objetos expostos, o público visitante e os mediadores dos museus de Ciências.

Espero que este trabalho possa contribuir para a compreensão das exposições com uma finalidade educativa, idealizadas por museus, especialmente as centradas em natureza, animais preservados e objetos expostos.

Com a realização desta pesquisa, pude obter mais informações acerca de visitantes em museus de ciências, não mais como espectadora, e sim como pesquisadora. Atrelado a isso, pude perceber o imenso valor educativo do ambiente de museu e sua contribuição como espaço não-formal de educação.

\section{REFERÊNCIAS}

ALMEIDA, A. Como se posicionam os professores perante a existência e utilização de jardins zoológicos e parques afins? Resultados de uma investigação. Educação e Pesquisa, São Paulo, v.34, n.2, p. 327-342, maio/ago - 2008.

CHAGAS, I. Aprendizagem não formal/formal das ciências. Relações entre os museus de ciência e as escolas - 1993

CONSTANTIN, A. C. C. Museus interativos de ciências: espaços complementares de educação? - 2000.

GODOY, A S. Introdução à pesquisa qualitativa e suas possibilidades, In Revista de Administração de Empresas, v.35, n.2, Mar./Abr. 1995a, p. 57-63. Pesquisa qualitativa. - tipos fundamentais, In Revista de Administração de Empresas, v.35, n.3, Mai./Jun. p. 20-29 - 1995

KELLERT, S. R. Kinship to mastery: biophilia in human evolution and development. Washington: Island Press, 1997.

LÜDKE, M. e ANDRÉ, M. Pesquisa em educação: abordagens qualitativas. São Paulo: EPU1986.

MINAYO, M. C. S. O desafio do conhecimento: pesquisa qualitativa em saúde. 4 ed. Rio de Janeiro: Hucitec-Abrasco - 1996.

QUEIROZ, G.; KRAPAS, S.; VALENTE, M. E.; DAVID, E.; DAMAS, E.; Willison, J. Educação ambiental em jardins botânicos: diretrizes para o desenvolvimento de estratégias individuais. Rio de Janeiro: Rede Brasileira de Jardins Botânicos - 2003. 